\title{
Submodule Based MPPT with Synchronous Buck Converter Under Dynamic Partial Shading Conditions
}

\author{
Mustafa Engin Başoğlu ${ }^{1+}$ (I) \\ ${ }^{1 *}$ Gümüşhane University, Electrical and Electronics Engineering Department, 29100, Gümüşhane, Turkey. (e-mail: menginbasoglu@ gumushane.edu.tr).
}

\section{ARTICLE INFO}

Received: Apr., 18. 202

Revised: Dec., 12. 2021

Accepted: Dec, 27. 2021

\section{Keywords:}

Photovoltaic

MPPT

Submodule

Synchronous buck

Perturb \& Observe

Corresponding author: $M$. E. Başoğlu

ISSN: 2536-5010 | e-ISSN: 2536-5134

DOI: https://doi.org/10.36222/ejt.919346

\section{ABSTRACT}

In order to obtain more power from photovoltaic (PV) modules under mismatching operating conditions, the submodule-based MPPT technique is an important solution. In this technique, since the power-voltage (P-V) curve of a submodule cannot be multi-peaked, the maximum power point (MPP) tracking (MPPT) is easily achieved through a DC-DC converter connected to each submodule. Since the P-V curve cannot be in a multi-peaked form, the maximum power can be obtained with a simple MPPT algorithm. For this reason, perturb \& observe $(\mathrm{P} \& \mathrm{O})$ algorithm can be chosen. In this study, the behaviour of a submodule-based MPPT with synchronous buck converter (SBC) is investigated for dynamic shading conditions. In addition, submodule-based MPPT and module-based MPPT technique were compared and the comparison was confirmed by simulation studies that submodule-based MPPT performed better. In this context, simulation studies were carried out for different shading conditions. According to the simulation results, the submodulebased MPPT approach achieves greater efficiencies to the module-based MPPT. In some simulations, when the module-based MPPT technique is used, the operation at the local MPP has been realized. In such cases, more advanced algorithms are needed. However, a simple algorithm is sufficient in submodule-based MPPT. The only disadvantage of this MPPT is the high hardware cost. However, the increase in efficiency obtained is at a level that can easily tolerate this cost.

\section{INTRODUCTION}

The desire to utilize renewable energy sources is one of the biggest motivations of the 21st century. Energy sources such as wind, water flow, rain, bio fuel, geothermal wave, tide offered by nature are based on the great energy power promised by the sun. Due to its potential, the sun has the capacity to meet the energy needs of the whole world. Despite this, the percentage of utilization from solar energy, in other words, the share of electricity generation from solar energy is at the level of 3\% as of the end of 2019 [1].

Electricity generation from the sun is carried out by PV cells. Since PV cells have p-n junction structure, the current equations of PV cells are exponential. Consequently, the P-V and current-voltage (I-V) characteristics are in nonlinear form. Since PV cells are semiconductor materials with a voltage of approximately $0.6 \mathrm{~V}$ and producing a maximum of $5 \mathrm{~W}$ power, their applications are very limited. For this reason, cells are connected in series to form submodules, submodules connected in series to form PV modules. On the other hand, PV cells can generate maximum power for only one current and voltage value. For this reason, the current and voltage values of the PV cells are continuously controlled, and the maximum possible power is generated.
Commercial PV modules are generally equipped with at least three bypass diodes. In order to avoid hot-spot problems in PV modules, these diodes are connected in reverse parallel to the submodules in the junction box in order to bypass the shadowed submodule and increase the possible maximum power to a certain extent [2].

Synchronous buck is a converter used in low voltage applications. In [3], zero voltage transition SBC has been investigated for small voltages. Switching losses are considerably reduced and efficiency increased compared to conventional buck converter. Performance of a SBC with MPPT controller has been evaluated in [4]. It is shown that an increase of around $12-13 \%$ was obtained in the output voltage and output current of the SBC. Submodule integrated MPPT has been realized in [5]. SBC with high efficiency and high energy density has been realized. It has been shown that with the sub-module-based approach, 20\% more energy is obtained compared to the module-based MPPT. In another study [6], a SBC was compared to the classical buck converter and the isolated buck converter. The SBC is recommended for UPS application [7]. It was determined that conduction losses decreased and efficiency increased by at least 5\% thanks to the MOSFET element used instead of diode in the SBC. A SBC is used in a study [8] where the advantages of distributed 
MPPT are presented. In this study, module level MPPT is proposed in systems where large power PV modules are used, and string level MPPT is proposed in systems using small power PV modules. Thanks to high frequency SBCs, the size has been reduced and submodule-based MPPT has been realized. In this way, a power increase of $27.55 \%$ was achieved. In another study [9], a distributed MPPT system using a common LC filter SBC whose outputs are serially connected is proposed. The optimum flow control-tracking algorithm has been implemented at the submodule level and small-scale incompatibility problems have been resolved. The performance of the SBC in a standalone system has been experimentally evaluated [10]. The efficiency change of the converter operated at different frequencies has been examined and it has been observed that the frequency has a serious effect on the efficiency. In [11], a new robust observer nonlinear control is proposed.

$\mathrm{SBC}$ is a circuit used for MPPT purposes in PV systems in order to obtain high efficiency in low voltage applications. For this purpose, in this study, the performance of the SBC in submodule and module-based MPPT applications has been investigated since the voltage level is generally small in the submodule-based MPPT approach. The following details are mentioned in the rest of the study. In the second section, the mathematical model and equivalent circuit of the classical buck converter are given and the working principle is explained. In addition, the advantages obtained with the use of a SBC are mentioned. In the following section, the MPPT algorithm used in the study is briefly explained. Then, the results of the simulation studies made to compare modulebased MPPT and submodule-based MPPT techniques are presented in the fourth section. In addition, comparative analyzes are made in this section. Finally, the results of the study are mentioned.

\section{BUCK CONVERTER UNDER STEADY STATE CONDITIONS}

Buck converter circuit is used in many areas such as LED drivers, telemetry systems, automotive industry, smart phones, battery charging, solar charging and motor control, which may require lower voltage than input voltage. As with other DC-DC converters, buck converters consist of at least one active switch, a diode, an inductance and a capacitor. Buck converters work on the principle of energy transfer of inductance. The circuit diagram of the buck converter is given in Figure 1. As seen in Figure 2, if a second active switch is used instead of a diode in the buck converter, a synchronous converter is obtained. In this case, the synchronous buck will have two active switches in the converter.

The working principle of buck converters depends on the principle of energy transfer in the inductance element. First, the energy stored in the inductance at a time interval of the period is transferred to the output in the remaining time of the period. Value of the inductance current can be continuous or discontinuous. If continuous mode of operation is taken as reference, because the inductance current is constantly changing, voltage is induced in the inductance according to the induction principle.


Figure 1. The circuit diagram of a buck converter a) classical b) Synchronous

\subsection{Synchronous Buck Converter}

In the $\mathrm{SBC}$, the $\mathrm{Q}_{1}$ and $\mathrm{Q}_{2}$ switches are turned on sequentially. PWM applied to $\mathrm{Q} 1$ is applied to $\mathrm{Q}_{2}$ by passing through the not logic gate. The important thing here is to ensure that the $\mathrm{Q}_{1}$ and $\mathrm{Q}_{2}$ switches are not turned on at the same time. If $\mathrm{Q}_{1}$ and $\mathrm{Q}_{2}$ are turned on at the same time, the input voltage source will be short-circuited. Therefore, a dead time is left for the $\mathrm{Q}_{2}$ switch to not transmit before the $\mathrm{Q}_{1}$ switch is turned off. When $\mathrm{Q}_{1}$ is turned on, there is a voltage equal to difference of input voltage and output voltage on the inductance element as presented in Fig. 2. Since this voltage is greater than zero, the current and energy of the inductance increase between $\mathrm{t}=0$ and $\mathrm{t}=\mathrm{t}_{\mathrm{on}}$. The time of $\mathrm{t}_{\mathrm{on}}$ is the conduction time of $\mathrm{Q}_{1}$ switch. Voltage and current change on inductance are defined as in Eq. (1) and Eq. (2), respectively.

$$
\begin{gathered}
v_{L}=V_{\text {in }}-V_{o} \\
v_{L}=L \frac{d i_{L}}{d t}=L \frac{\Delta i_{L}}{\Delta t} \rightarrow \Delta i_{L}=\frac{\left(V_{\text {in }}-V_{o}\right) D T_{P}}{L}
\end{gathered}
$$



Figure 2. Equivalent circuit when $\mathrm{Q}_{1}$ turned on $\left(\mathrm{Q}_{2}\right.$ turned off $)$

$\mathrm{V}_{\mathrm{L}}$ is the voltage of inductance, $\mathrm{V}_{\text {in }}$ is the input voltage, $\mathrm{Vo}_{\mathrm{O}}$ is the output voltage of the SBC, $\mathrm{D}$ is the duty ratio, $\mathrm{f}$ is the switching frequency, $L$ is the value of inductance and $T_{p}$ is the period of the PWM in Eq. (1) and Eq. (2). When $Q_{1}$ is turned off, $\mathrm{Q}_{2}$ switches on after a very small dead time. When $\mathrm{Q}_{2}$ is turned on, as it can be understood from Figure 3, the connection between the source and the output is disconnected. During this period, there is a voltage of $-\mathrm{V}_{\mathrm{o}}$ on the inductance and the energy of the inductance decreases between $t=t_{\text {on }}$ and $t=T_{p}$. At the end of a period, the principle of transferring energy on inductance has been realized. In steady state, the net energy on the inductance is expected to be zero. The voltage, current and energy changes on the inductance are defined as given in Eq. (3), Eq. (4) and Eq. (5), respectively. 


$$
\begin{gathered}
v_{L}=-V_{o} \\
v_{L}=L \frac{d i_{L}}{d t}=L \frac{\Delta i_{L}}{\Delta t} \rightarrow \Delta i_{L}=\frac{-V_{o} D}{L f} \\
W_{L, \text { on }}=\frac{1}{2} L\left(I_{L \max }^{2}-I_{L \text { min }}^{2}\right)=\left|W_{L, \text { off }}\right|
\end{gathered}
$$

$\mathrm{W}_{\mathrm{L} \text {,on }}$ and $\mathrm{W}_{\mathrm{L} \text {,off }}$ are the energy values of the inductance at certain times of the period. $\mathrm{I}_{\mathrm{Lmin}}$ and $\mathrm{I}_{\mathrm{Lmax}}$ are the minimum and maximum values of the inductance current, respectively.



\subsection{Design Procedure}

In this section, the design procedure for the design of the SBC power stage is given. Duty ratio of a buck converter is calculated as in Eq. (6).

$$
D=\frac{V_{o}+V_{\text {low }}}{V_{\text {in }}+V_{\text {high }}}
$$

In Eq. (6), $\mathrm{V}_{\text {low }}$ and $\mathrm{V}_{\text {high }}$ low side and high side are MOSFET voltage drops, respectively. Inductance is selected for continuous current mode. For this purpose, the current fluctuation percentage can be chosen between $15 \%$ and $30 \%$. In this framework, inductance is calculated as follows.

$$
L=\frac{\left(V_{i n}-V_{h i g h}-V_{o}\right) D T_{P}}{\Delta I_{L}}
$$

The other element of the LC filter is the capacitor. Capacitor value calculation is defined in Eq. (8).

$$
C=\frac{\Delta I_{L}}{8 f \Delta V_{o}}
$$

\section{SIMULATION STUDIES}

Many approaches, methods or techniques have been proposed for MPPT in PV systems [12-17]. Although some hardware-based studies are carried out, especially in incompatible working conditions such as partial shading, the number of algorithm-based studies is quite high. In algorithmbased studies, the need for sensors, microcontroller power, heavy mathematical operations required by the running algorithm, etc. stand out as the problems encountered. In this study, it has been focused on enhancing MPPT performance in hardware and for this purpose, SBCs have been used and some determinations have been made for dynamic and rapidly changing shading conditions with a simple algorithm. The performances of module-based MPPT and submodule-based MPPT were compared for two different shading situations. The technical features of the PV module used are given in Table I, and main properties of the SBC are given in Table II.

TABLE I

MAIN SPECIFICATIONS OF THE PV MOdULE [18]

\begin{tabular}{lc}
\hline \hline Bosch PV Module c-Si M 48 & Value \\
\hline Short circuit current & $8.5 \mathrm{~A}$ \\
Open circuit voltage & $28.9 \mathrm{~V}$ \\
Maximum power voltage & $23.4 \mathrm{~V}$ \\
Maximum power current & $7.9 \mathrm{~A}$ \\
Maximum power & $180 \mathrm{~W}$ \\
Bypass diodes & 3 \\
\hline \hline Submodule - Bosch & Value \\
\hline Maximum power voltage & $7.8 \mathrm{~V}$ \\
Maximum power current & $7.9 \mathrm{~A}$ \\
Maximum power & $60 \mathrm{~W}$ \\
\hline
\end{tabular}

TABLE II

MAIN SPECIFICATIONS OF THE SBC

\begin{tabular}{lc}
\hline \hline Features & Value \\
\hline Input / output capacitor & $630 \mu \mathrm{F} / 63 \mu \mathrm{F} \mu \mathrm{F}$ \\
Inductance & $0.5 \mathrm{mH}$ \\
Switching frequency & $100 \mathrm{kHz}$ \\
MOSFET on resistance $\left(\mathrm{R}_{\text {dson }}\right)$ & $0.025 \Omega$ \\
Initial value of duty ratio $\left(\mathrm{D}_{\text {first }}\right)$ & 0.4 \\
Load resistance $\left(\mathrm{R}_{\text {load }}\right)$ & $1 \Omega$ \\
\hline \hline
\end{tabular}

Simulink model of submodule-based MPPT is given in Figure 4. As can be seen from this model, each submodule is connected to the SBC and three different MPPT operations are performed. An example of dynamic partial shading is given in Figure 5. As can be seen from this figure, there are five different irradiation conditions. PV module consists of three submodules and these submodules consist of 32 serial cells (one square $=$ two cells). These submodules are defined as SPV-1, SPV-2 and SPV-3. A bypass diode is not required for submodule MPPT. In the first simulation study, the irradiation values applied to the submodules change in 0.1 seconds periods. This means that the radiation on the PV module changes dynamically. The change of the irradiation on the submodules within a certain period means the change of the MPP.

As can be seen in Fig. 5, an example of a PV module is exposed to five different irradiation profiles at 0.1 seconds intervals. In this example, the irradiation changes of each submodule are given in Irradiation SPV-1, Irradiation SPV-2 and Irradiation SPV-3, respectively in the Figure 6. In the submodule-based MPPT approach, there is a single MPP P-V curve for each submodule. P-V curves of the submodules are given in Figure 7 for five different radiation conditions. In this way, MPPT operation can be achieved with a simple Hill Climbing (HC) algorithm. The results of the submodule-based MPPT simulation for the dynamic shading condition are given in Figure 6. As can be seen from the results, the irradiation showed a rapid change in 0.1 seconds intervals. However, since there is only one MPP in the P-V curve of each submodule, the submodules operate at the MPP after a while. In this study, although different tracking efficiency and convergence times were obtained for submodules, global MPPT (GMPPT) was provided at steady state. The efficiency values obtained in 0.5 seconds are given in Table III. 
EUROPEAN JOURNAL OF TECHNIQUE, Vol.11, No.2, 2021

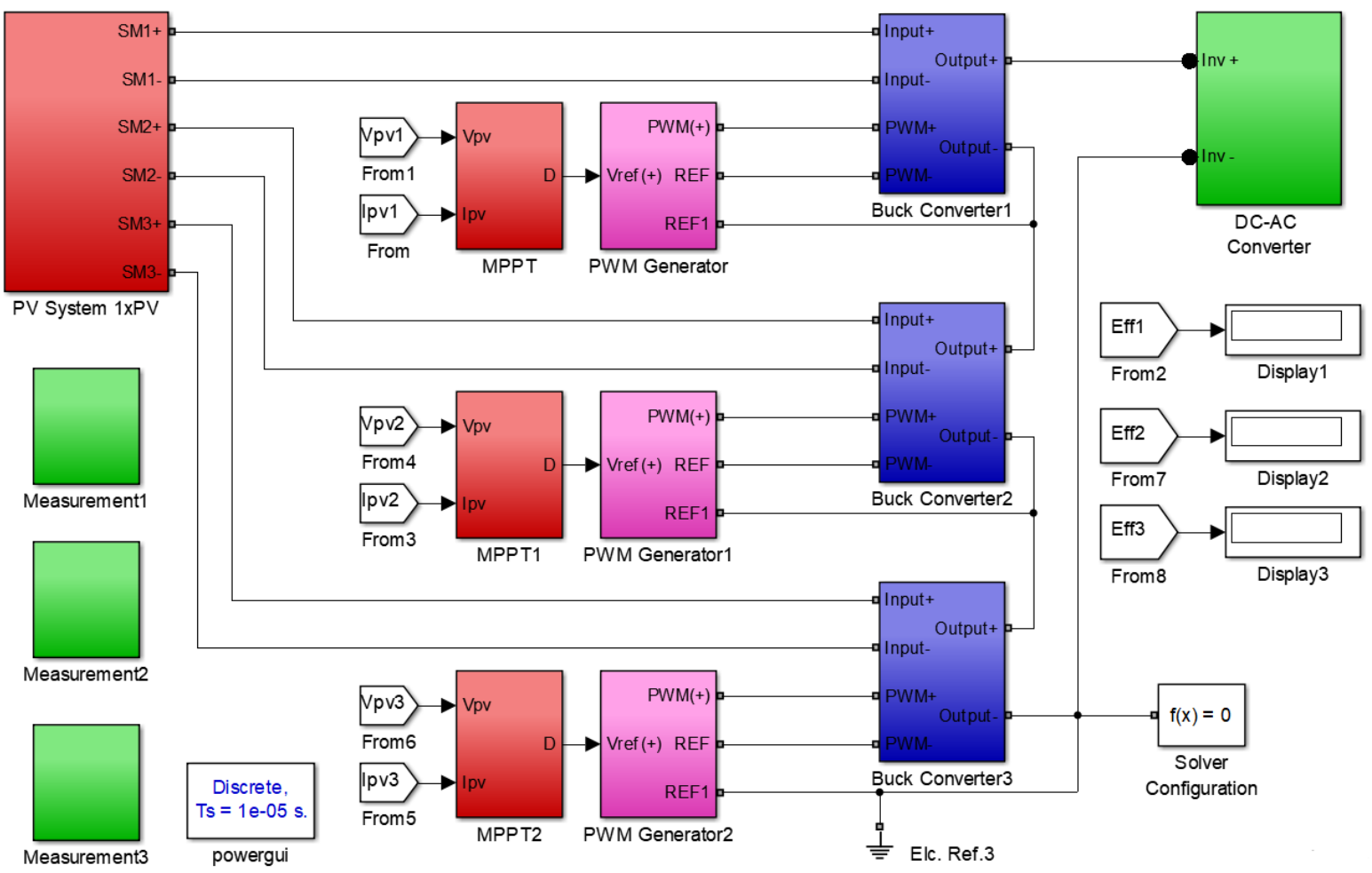

Figure 4. Simulink model of the submodule MPPT approach
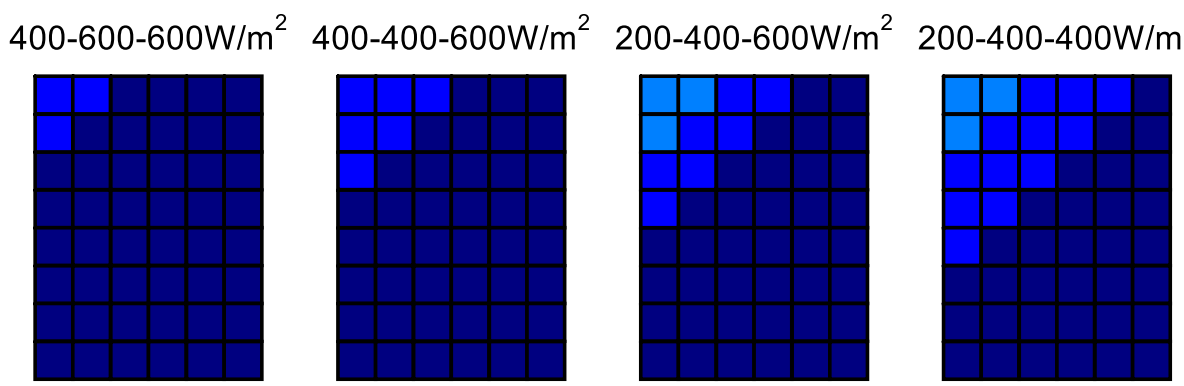

$200-400-400 \mathrm{~W} / \mathrm{m}^{2}$

Figure 5. Dynamic partial shading scenario-1
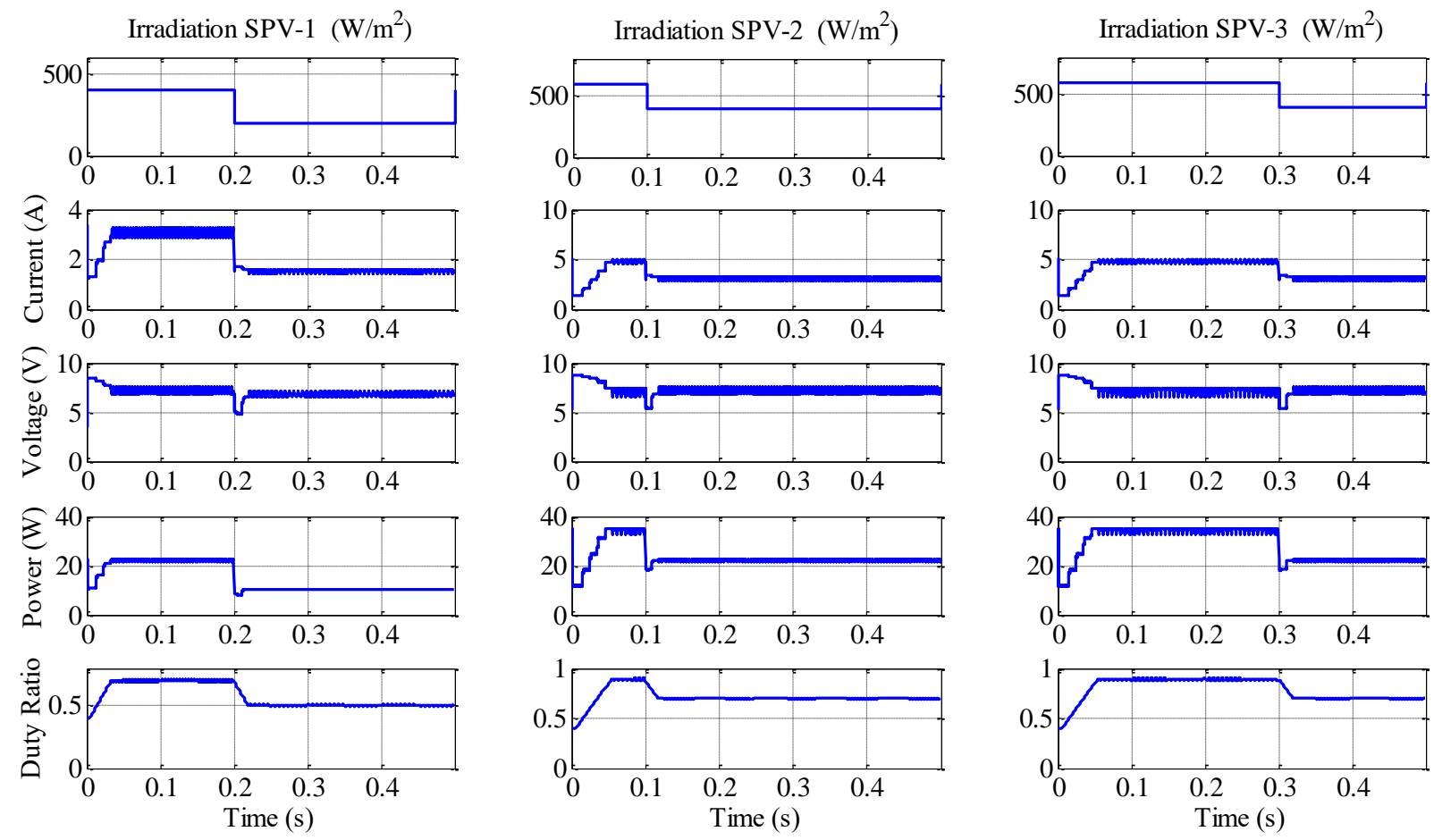

Figure 6. Simulation results of submodule-based MPPT for PSC-1 
TABLE III

SIMULATION RESULTS FOR DYNAMIC SHADING SCENARIO-1

\begin{tabular}{|c|c|c|c|c|c|c|c|c|}
\hline \multicolumn{3}{|c|}{ Irradiation Profile $\left(\mathrm{W} / \mathrm{m}^{2}\right)$} & \multicolumn{3}{|c|}{ Power $(W)$} & \multicolumn{3}{|c|}{$\begin{array}{c}\text { Tracking Efficiency } \\
\text { Submodule-based MPPT }\end{array}$} \\
\hline SPV-1 & SPV-2 & SPV-3 & $\mathbf{P}_{\text {max-SPV1 }}$ & $\mathbf{P}_{\max -\mathrm{SPV} 2}$ & $\mathbf{P}_{\max -\mathrm{SPV3}}$ & SPV-1 & SPV-2 & SPV-3 \\
\hline 400 & 600 & 600 & 22.38 & 34.75 & 34.75 & \multirow{5}{*}{96.16} & \multirow{5}{*}{94.72} & \multirow{5}{*}{93.90} \\
\hline 400 & 400 & 600 & 22.38 & 22.38 & 34.75 & & & \\
\hline 200 & 400 & 600 & 10.53 & 22.38 & 34.75 & & & \\
\hline 200 & 400 & 400 & 10.53 & 22.38 & 22.38 & & & \\
\hline 200 & 400 & 400 & 10.53 & 22.38 & 22.38 & & & \\
\hline \multicolumn{3}{|c|}{ Irradiation Profile $\left(\mathrm{W} / \mathrm{m}^{2}\right)$} & \multicolumn{3}{|c|}{ Power $(\mathbf{W})$} & \multicolumn{3}{|c|}{ Tracking Efficiency (\%)94.72 } \\
\hline SPV-1 & SPV-2 & SPV-3 & \multicolumn{3}{|c|}{$\mathrm{P}_{\max }$} & \multicolumn{3}{|c|}{ Module-based MPPT } \\
\hline 400 & 600 & 600 & \multicolumn{3}{|c|}{76.51} & \multirow{5}{*}{\multicolumn{3}{|c|}{96.79}} \\
\hline 400 & 400 & 600 & \multicolumn{3}{|c|}{71.34} & & & \\
\hline 200 & 400 & 600 & \multicolumn{3}{|c|}{48.92} & & & \\
\hline 200 & 400 & 400 & \multicolumn{3}{|c|}{44.53} & & & \\
\hline 200 & 400 & 400 & \multicolumn{3}{|c|}{44.53} & & & \\
\hline
\end{tabular}

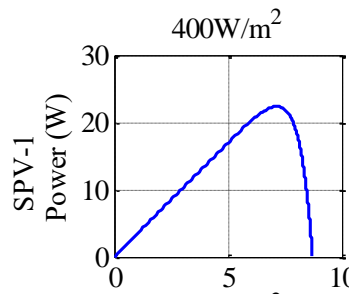

$600 \mathrm{~W} / \mathrm{m}^{2}$

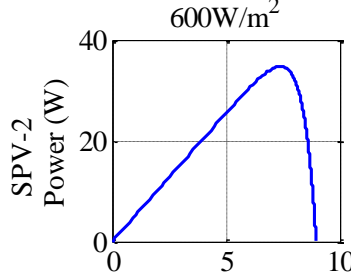

$600 \mathrm{~W} / \mathrm{m}^{2}$



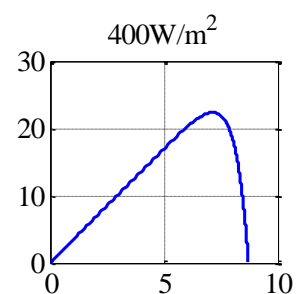

$400 \mathrm{~W} / \mathrm{m}^{2}$
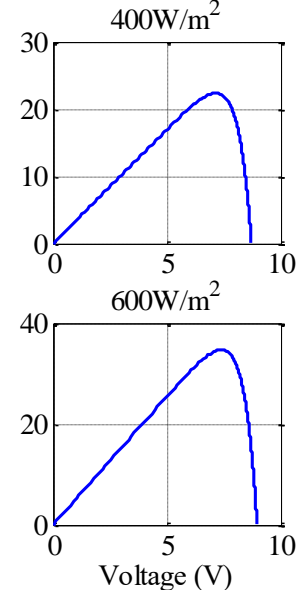

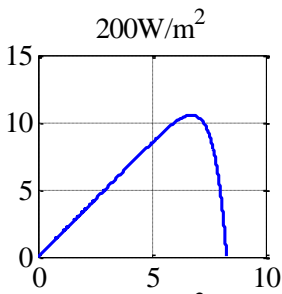

$400 \mathrm{~W} / \mathrm{m}^{2}$
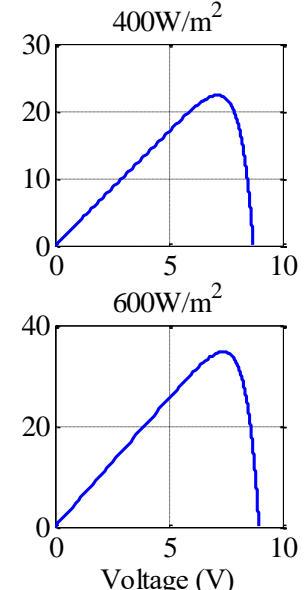

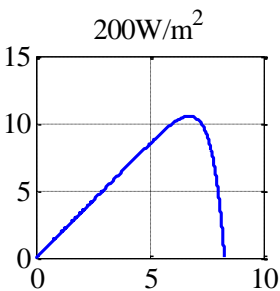

$400 \mathrm{~W} / \mathrm{m}^{2}$
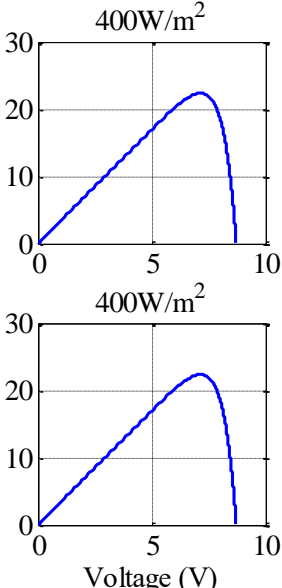

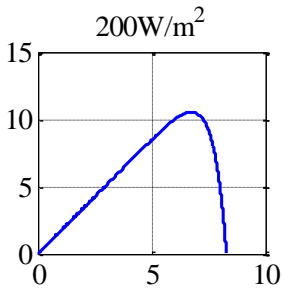

$400 \mathrm{~W} / \mathrm{m}^{2}$
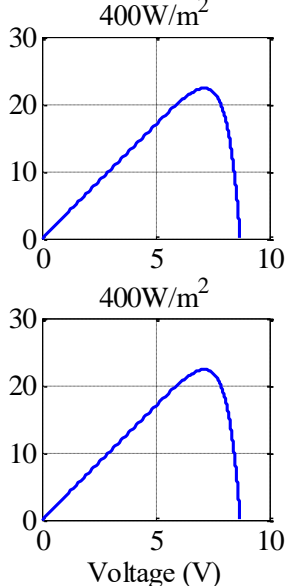

Figure 7. Dynamic P-V curves of the submodules for PSC-1

If module-based MPPT is applied with a typical HC algorithm for the same dynamic shading situation, it will be observed that the success of GMPPT depends heavily on the conditions at the starting point of the tracking. Because in a HC based MPPT, the algorithm is stuck at the first hill in the $\mathrm{P}-\mathrm{V}$ curve. However, it is not known whether this point is global maximum power point (GMPP). In other words, GMPPT occurs depending on the initial value of the PWM applied to the MOSFET in the SBC. For dynamic shading scenario-1, module-based MPPT enabled operation at GMPP as presented in Figure 8. Five different irradiation conditions indicated in Table III are applied at 0.1 seconds intervals and there are five different $\mathrm{P}-\mathrm{V}$ curves for these five cases. These curves given in Figure 8 are different when compared to the $\mathrm{P}-\mathrm{V}$ curves obtained for the submodule-based MPPT. In the module-based MPPT, diodes connected to submodules in reverse parallel have created multiple peaks in the P-V curves. Therefore, global maximum power values are smaller than submodule-based MPPT. Simulation results for module-based MPPT are presented in Figure 9.
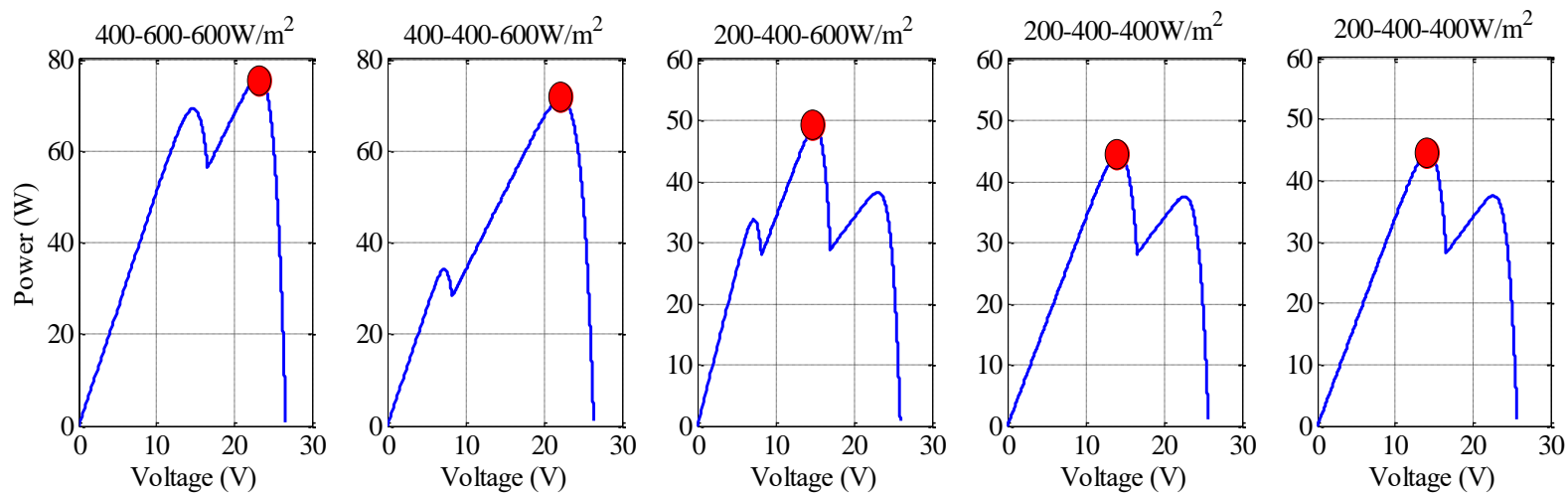

Figure 8. P-V curves of the PV module (when module-based MPPT is applied) 
EUROPEAN JOURNAL OF TECHNIQUE, Vol.11, No.2, 2021
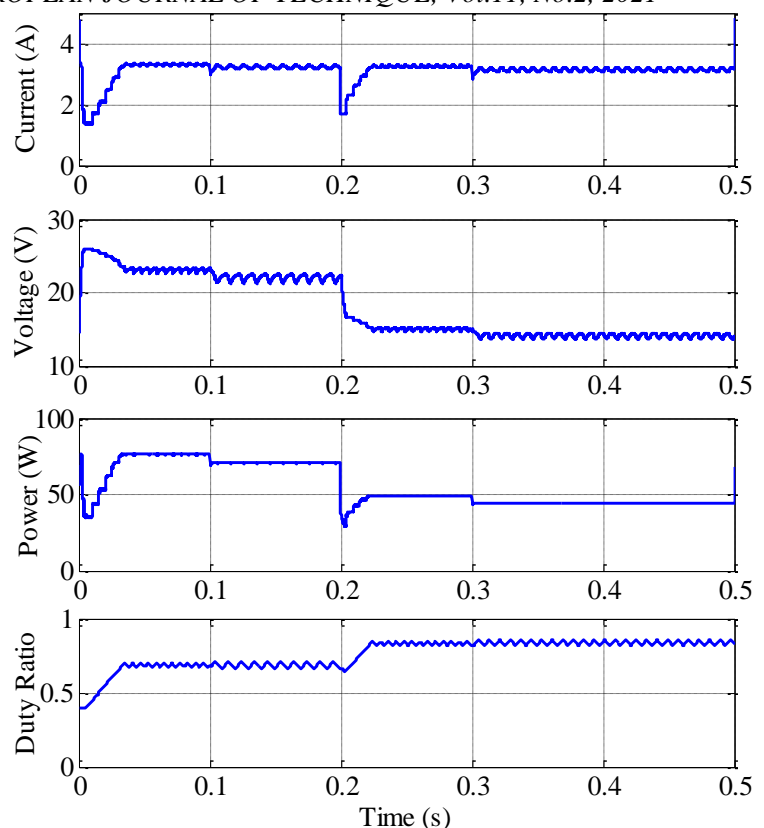

Figure 8. Simulation results of module based MPPT for PSC-1

Submodule-based MPPT and module-based MPPT simulations are performed for dynamic partial shading scenario-2. The panel view for this situation is given in Figure. 10. According to the simulation results, when there is a radiation change, it is seen that the $\mathrm{P} \& \mathrm{O}$ algorithm reaches its maximum power point in a short time. The power values that the submodules operate can be seen in Figure 11, and the maximum power values that the submodules can produce in the MPP can be seen from the P-V curves in Figure 12. Tracking efficiencies for submodules are $94.48 \%, 93.12 \%$ and $91.41 \%$ in 0.5 seconds. Table IV lists the power values and tracking efficiencies for the submodules at the MPP.

MPPT operation performed at module level is expressed as GMPPT. Because in the P-V curve of a partially shaded PV module, the number of MPPs changes depending on the dynamic shading condition and the amount of bypass diode. In this case, the MPPT process becomes difficult. In the module level MPPT simulation, it is understood from the P-V curves given in Figure 13 that GMPPT cannot be performed for some shading conditions. From this figure, it can be concluded that the PV module sometimes works in local MPP and sometimes in GMPP. Tracking efficiency in PV module operating in local MPP for a certain period was calculated as $82.87 \%$. For the same dynamic shading condition, the tracking efficiency in the submodule-based MPPT approach is given in Table IV, where it ranges between $91.41 \%$ and $94.48 \%$. These efficiency values are given for 0.5 seconds, and it is possible to predict that the efficiency will reach values above $99 \%$ in submodule-based MPPT after a while. Because the PV module performs continuously in GMPP. On the other hand, in module-level MPPT, the P\&O algorithm cannot prevent operation in local MPP. For this reason, achieving an efficiency level of $90 \%$ in module level MPPT is not possible with the current algorithm choice. Simulation results of module level MPPT are given in Figure 13. When the GMPP points are examined in the $\mathrm{P}-\mathrm{V}$ curves given in Figure 12, it is seen that the PV module performs at local MPP when the irradiation is $200-200-400 \mathrm{~W} / \mathrm{m}^{2}$ and $600-600-200 \mathrm{~W} / \mathrm{m}^{2}$.

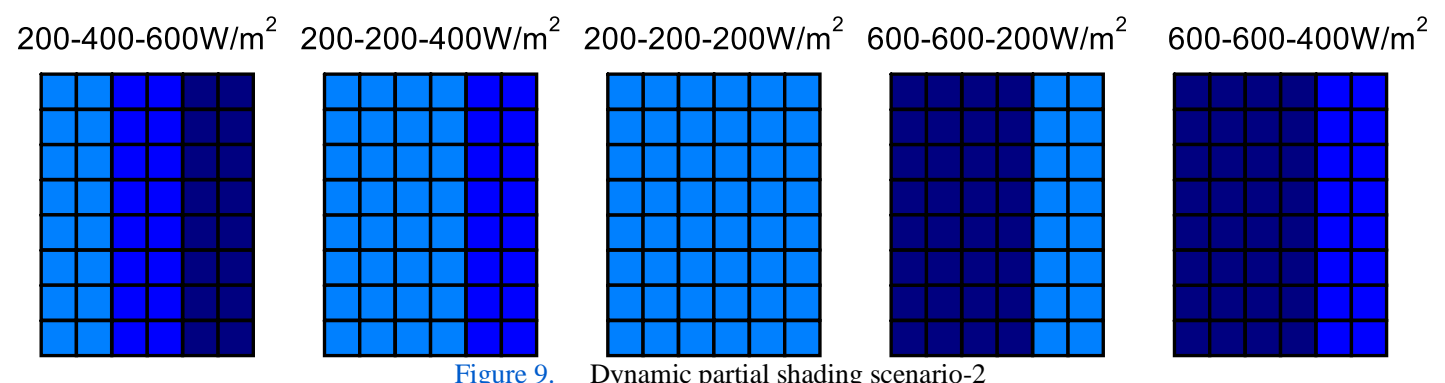

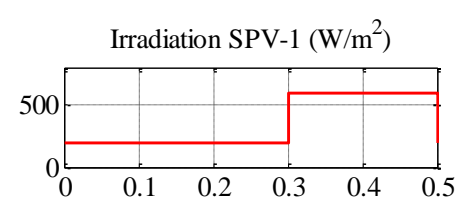
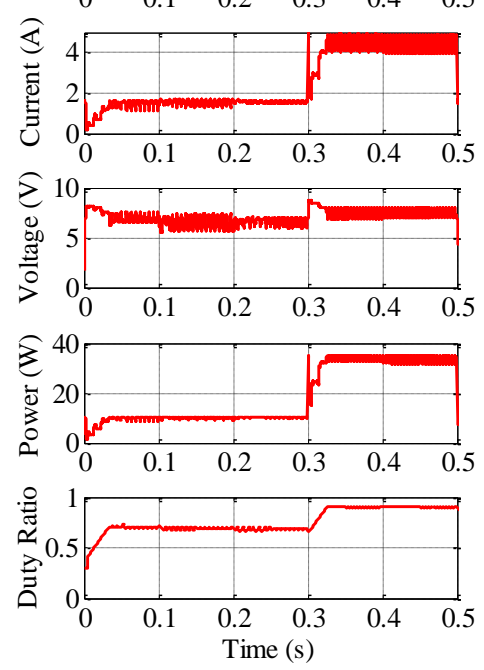

Figure 10. Simulation results of submodule-based MPPT for PSC-2
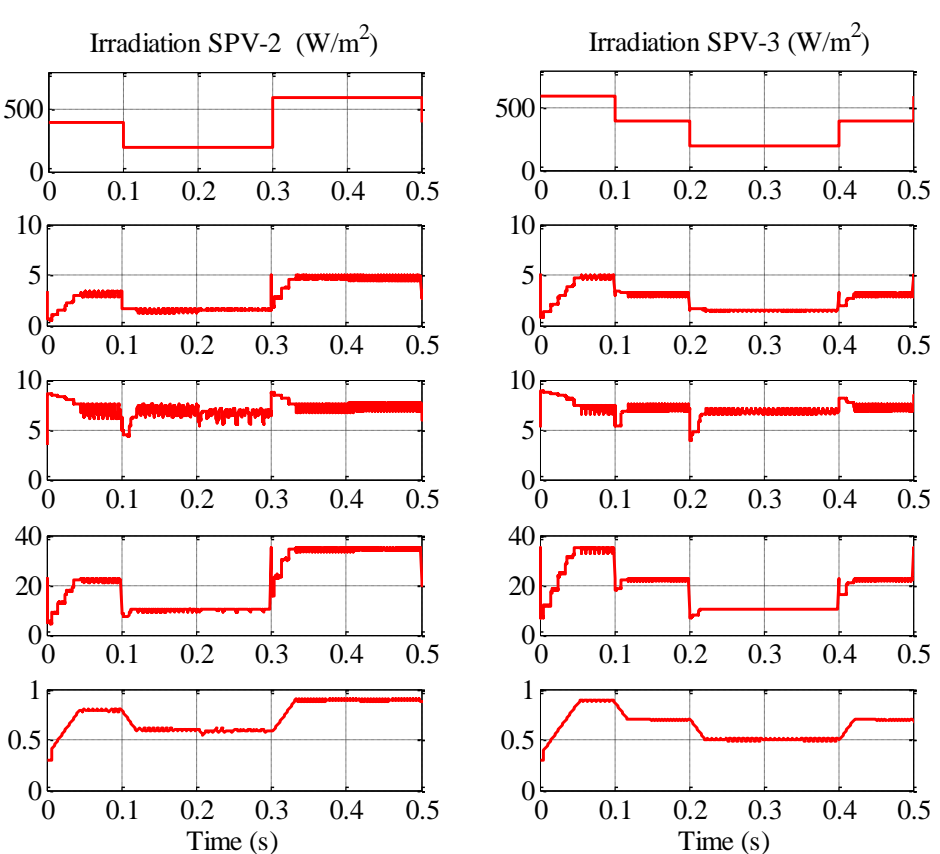
TABLE IV

SiMUlation RESUlTS FOR DYNAMIC SHADING SCENARIO-2

\begin{tabular}{|c|c|c|c|c|c|c|c|c|}
\hline \multicolumn{3}{|c|}{ Irradiation Profile $\left(\mathrm{W} / \mathrm{m}^{2}\right)$} & \multicolumn{3}{|c|}{ Power (W) } & \multicolumn{3}{|c|}{$\begin{array}{c}\text { Tracking Efficiency } \\
\text { Submodule-based MPPT }(\%)\end{array}$} \\
\hline SPV-1 & SPV-2 & SPV-3 & $\mathbf{P}_{\text {max-SPV1 }}$ & $\mathbf{P}_{\text {max-SPV2 }}$ & $\mathbf{P}_{\text {max-SPV3 }}$ & SPV-1 & SPV-2 & SPV-3 \\
\hline 200 & 400 & 600 & 10.53 & 22.38 & 34.75 & \multirow{5}{*}{94.48} & \multirow{5}{*}{93.12} & \multirow{5}{*}{91.41} \\
\hline 200 & 200 & 400 & 10.53 & 10.53 & 22.38 & & & \\
\hline 200 & 200 & 200 & 10.53 & 10.53 & 10.53 & & & \\
\hline 600 & 600 & 200 & 34.75 & 34.75 & 10.53 & & & \\
\hline 600 & 600 & 400 & 34.75 & 34.75 & 22.38 & & & \\
\hline \multicolumn{3}{|c|}{ Irradiation Profile $\left(\mathrm{W} / \mathrm{m}^{2}\right)$} & \multicolumn{3}{|c|}{ Power (W) } & \multicolumn{3}{|c|}{ Tracking Efficiency (\%) } \\
\hline SPV-1 & SPV-2 & SPV-3 & \multicolumn{3}{|c|}{$\mathrm{P}_{\max }$} & \multicolumn{3}{|c|}{ Module-based MPPT } \\
\hline 200 & 400 & 600 & \multicolumn{3}{|c|}{48.92} & \multirow{5}{*}{\multicolumn{3}{|c|}{82.87}} \\
\hline 200 & 200 & 400 & \multicolumn{3}{|c|}{34.25} & & & \\
\hline 200 & 200 & 200 & \multicolumn{3}{|c|}{31.58} & & & \\
\hline 600 & 600 & 200 & \multicolumn{3}{|c|}{68.81} & & & \\
\hline 600 & 600 & 400 & \multicolumn{3}{|c|}{76.51} & & & \\
\hline
\end{tabular}
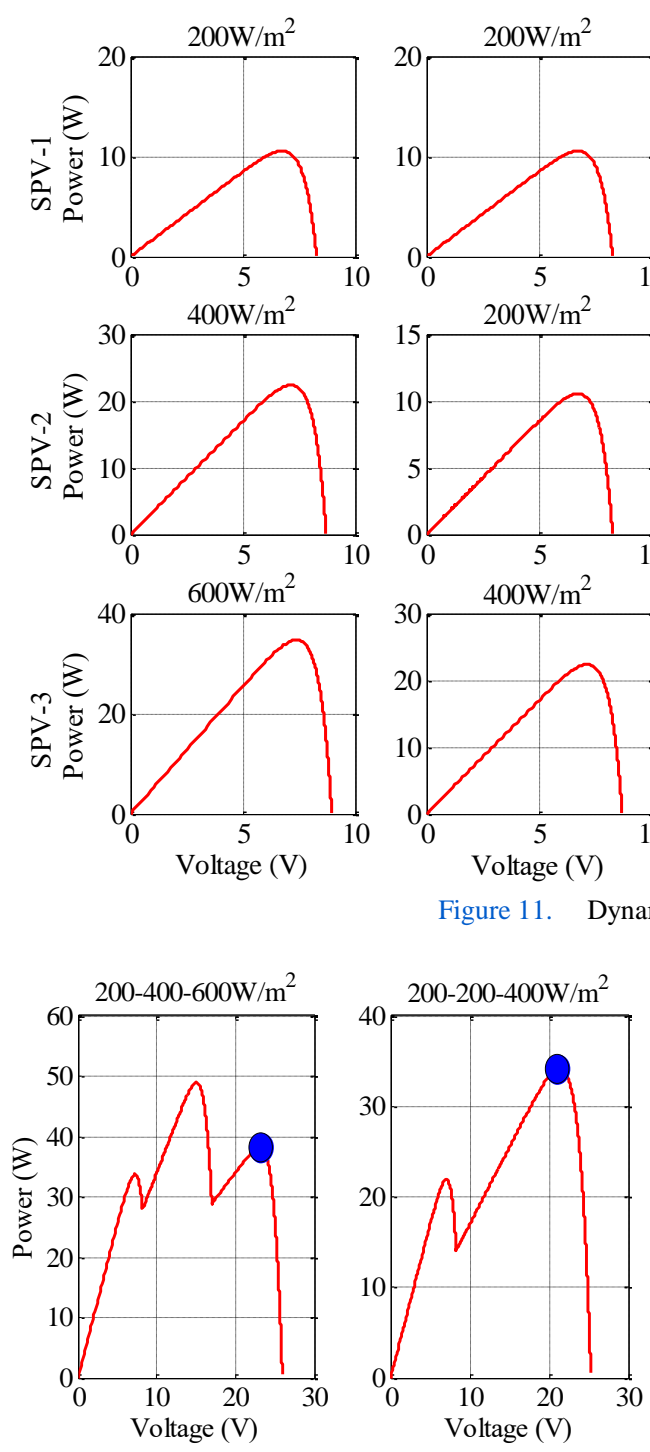

Figure 12


Figure 11. Dynamic P-V curves of the submodules for PSC-2

\section{DISCUSSIONS}

In this section, the simulation results obtained between MPPT at the submodule level and the module level MPPT have been evaluated and compared. As stated in the previous sections, the maximum power that can be obtained in MPPT realized at the submodule level is the sum of the powers generated by all submodules under the current irradiation conditions. The theoretical maximum power is defined in Eq. (9).
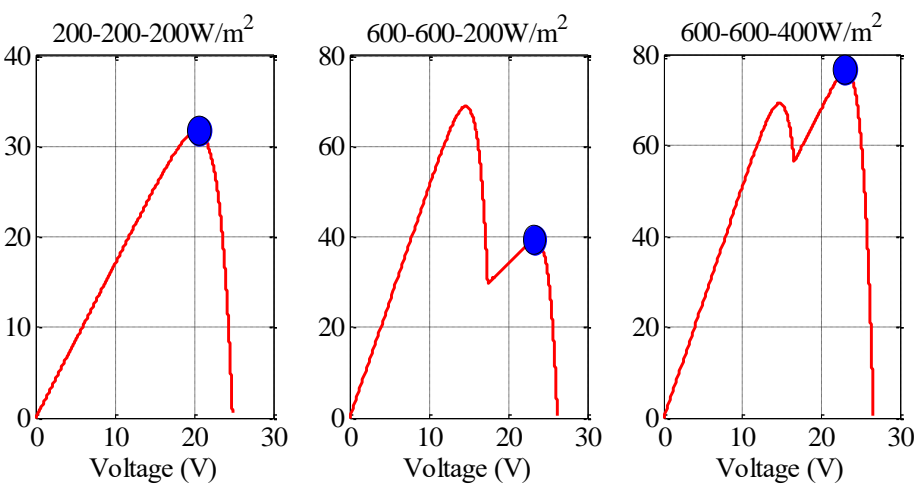

$$
P_{s b m}=P_{\text {max } \_S P V 1}+P_{\text {max } \_S P V 2_{2}}+P_{\text {max } \_S P V 3}
$$

In Eq. (9), $P_{\text {sbm }}$ is the sum of the power generated by the submodules, $\mathrm{P}_{\text {max_SB1} 1}, \mathrm{P}_{\max \_\mathrm{SB} 2}$ and $\mathrm{P}_{\max \_\mathrm{SB} 3}$ are the theoretical maximum power values of the submodules, respectively. In Eq. (10), the formula defining the sum of the powers generated by the submodules ate steady state is given.

$$
P_{s b m, \text { real }}=P_{S P V 1}+P_{S P V 2}+P_{S P V 3}
$$


An index has been defined to determine the performance difference between submodule based MPPT and module based MPPT. This index is defined in Eq. (11).

$\operatorname{diff}(\%)=100 \frac{P_{\text {sbm,real }}-P_{m, \text { real }}}{P_{\text {sbm,real }}}$
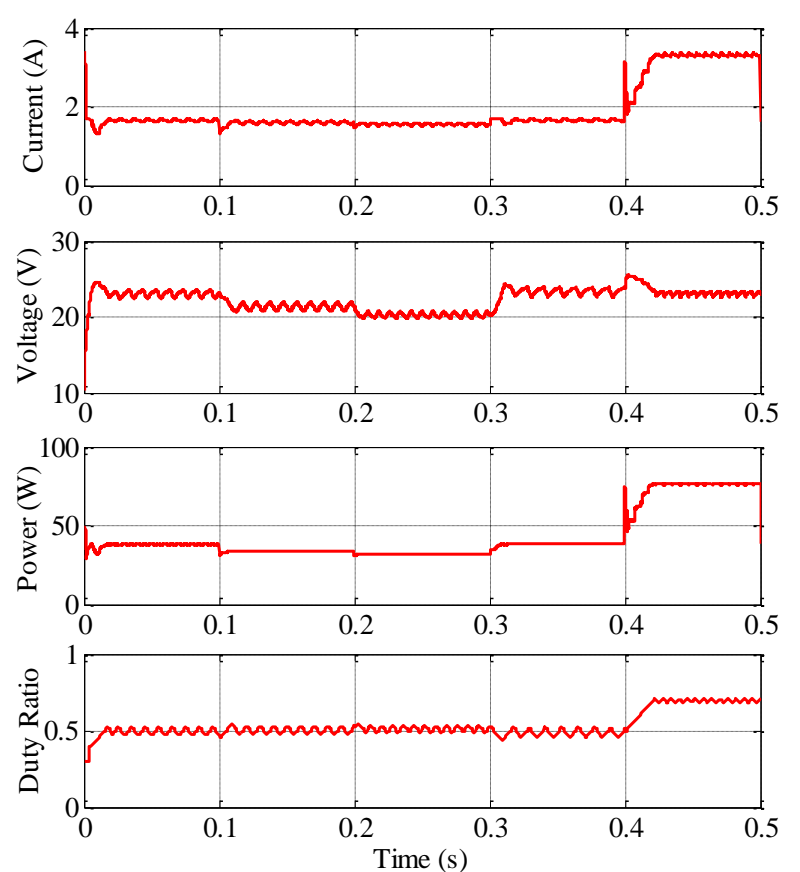

Figure 13. Simulation results of the module based MPPT for PSC-2

In this study, two different dynamic shading conditions are defined and two MPPT approaches are compared using SBC and $\mathrm{P} \& \mathrm{O}$ algorithm. The comparison is made on the power generated under the same conditions. In the submodule-based MPPT technique, MPPT was performed independently in each submodule and the total power to be generated theoretically was defined as the maximum power as given in Table V. As can be seen in Table $\mathrm{V}$, the theoretical maximum power has been generated under all irradiation conditions thanks to the flexibility of the submodule-based MPPT approach. In modulebased MPPT, even if GMPPT is realized, since MPPT is not as flexible as submodule-based MPPT, the maximum possible power value can never be as much as in the submodule-based MPPT technique. According to the first simulation results, submodule-based MPPT produced around $27 \%$ more power than module based MPPT. The maximum power that each submodule can produce can be checked from Table III and Table IV, and if it is calculated according to Eq. (9), the values in Table V can be obtained. Similar analyzes can be made for the second simulation results. According to Table V, a power increase of up to $27 \%$ has been achieved in submodule based MPPT

\section{CONCLUSION}

In this study, partial shading, which is one of the factors affecting the power to be generated in photovoltaic systems, is discussed. In order to avoid complexity, a simple system consisting of a single PV module has been considered and the performances of submodule based MPPT and module based MPPT under dynamic shading conditions have been investigated. In this context, since submodules have small voltage, a SBC was used and $\mathrm{P} \& \mathrm{O}$ was preferred as MPPT algorithm. According to the simulation studies carried out, the MPPT performed at the module level operates at lower efficiency than the MPPT performed at the submodule level. Although MPPT at submodule level is more complex and costly hardware, the GMPPT operation can be performed perfectly with a simpler algorithm. On the other hand, complex algorithms are needed for module-based MPPT to provide GMPPT perfectly. However, in any case there will be a lower power generation than the power obtained in the submodule level MPPT.

TABLE V

EVALUATIONS OF THE SimUlation RESUlts

\begin{tabular}{|c|c|c|c|c|c|}
\hline & Irradiation Profile $\left(\mathrm{W} / \mathrm{m}^{2}\right)$ & & \multicolumn{3}{|c|}{ Power $(W)$} \\
\hline No & SPV-1/SPV-2/SPV-3 & Max. Power & Submodule & Module & Diff. (\%) \\
\hline \multirow{6}{*}{1} & $400-600-600$ & 91.88 & 91.88 & 76.51 & 16.72 \\
\hline & $400-400-600$ & 79.51 & 79.51 & 71.34 & 10.27 \\
\hline & $200-400-600$ & 67.66 & 67.66 & 48.92 & 27.69 \\
\hline & $200-400-400$ & 55.29 & 55.29 & 44.53 & 19.46 \\
\hline & $200-400-400$ & 55.29 & 55.29 & 44.53 & 19.46 \\
\hline & Irradiation Profile $\left(\mathrm{W} / \mathrm{m}^{2}\right)$ & & \multicolumn{3}{|c|}{ Power (W) } \\
\hline \multirow{6}{*}{2} & SPV-1/SPV-2/SPV-3 & Max. Power & Submodule & Module & Diff. (\%) \\
\hline & $200-400-600$ & 67.66 & 67.66 & 48.92 & 27.69 \\
\hline & $200-200-400$ & 43.44 & 43.44 & 34.25 & 21.15 \\
\hline & $200-200-200$ & 31.58 & 31.58 & 31.58 & 0 \\
\hline & $600-600-200$ & 80.53 & 80.53 & 68.81 & 14.55 \\
\hline & $600-600-400$ & 91.88 & 91.88 & 76.51 & 16.73 \\
\hline
\end{tabular}

\section{REFERENCES}

[1] IEA Renewable Energy Market Update Outlook for 2020 and 2021, https://www.iea,org/reports/solar-pv, (accessed time: 06.04.2021)

[2] M.E. Başoğlu and B. Çakır, "A novel voltage-current characteristic based global maximum power point tracking algorithm in photovoltaic systems", Energy, vol. 112, pp. 153-163, 2016.

[3] A. K. Panda and K. Aroul, "A novel technique to reduce the switching losses in a synchronous buck converter", presented at the International Conference n.on Power Electronics, Drives and Energy Systems, New Delhi, India, 12-15 December, 2006.
[4] N. Z. Yahaya and A. A. A. A. Zamir, "Performance evaluation of SRBC circuit using MPPT controller", presented at the IEEE Symposium on Industrial Electronics and Applications, Bandung, Indonesia, 23-26 September, 2012.

[5] R. C. N. Pilawa-Podgurski and D. J. Perreault, "Submodule integrated distributed maximum power point tracking for solar photovoltaic applications", IEEE Transactions on Power Electronics, vol. 28, no. 6, pp. 2957-2967, 2013.

[6] Z. Iqbal, U. Nasir, M. T. Rasheed and K. Munir, "A comparative analysis of synchronous buck, isolated buck and buck converter" 
presented at the $15^{\text {th }}$ International Conference on Environment and Electrical Engineering, Rome, Italy, 10-13 June, 2015.

[7] J. Sreedhar and B. Basavaraju, "Design and analysis of synchronous buck converter for UPS application", presented at the International Conference on Advances in Electrical, Electronics, Information, Communication and Bio-Informatics, Chennai, India, 27-28 February, 2016.

[8] H. Luo, H. Wen, X. Li, L. Jiang and Y. Hu, "Synchronous buck converter based low-cost and high-efficiency sub-module DMPPT PV system under partial shading conditions", Energy Conversion and Management, vol. 126, pp. 473-487, 2016.

[9] F. Wang, T. Zhu, F. Zhuo, H. Yi and S. Shi, "Submodule level distributed maximum power point tracking PV optimizer with and integrated architecture", Journal of Power Electronics, vol. 17, no. 5, pp. 1308-1316, 2017.

[10] K. Pal and M. Pattnaik, "Performance of a synchronous buck converter for a standalone PV system: an experimental study", presented at the $1^{\text {st }}$ International Conference on Energy, Systems and Information Processing, Chennai, India, 4-6 July 2019.

[11] S. Abdelmalek, A. Dali, A. Bakdi and M. Bettayeb, "Design and experimental implementation of a new robust observer-based nonlinear controller for DC-DC buck converters", Energy, vol. 213, Article Number: 118816, 2020.

[12] M. E. Başoğlu and B. Çakır, "Experimental evaluations of global maximum power point tracking approaches in partial shading conditions", presented at the IEEE International Conference on Environment and Electrical Engineering, Milan, Italy, 6-9 June 2017.

[13] M. E. Başoğlu and B. Çakır, "Hybrid global maximum power point tracking approach for photovoltaic power optimisers", IET Renewable Power Generation, vol. 12, no. 8, pp. 875-882, 2018.

[14] M. E. Başoğlu, "An improved $0.8 \mathrm{~V}_{\mathrm{oc}}$ model based GMPPT technique for module level photovoltaic power optimizers", IEEE Transactions on Industry Applications, vol. 55, no.2, pp. 1913-1921, 2019.

[15] M. E. Başoğlu, "Analyzes of flyback DC-DC converter for submodule level maximum power point tracking in off-grid photovoltaic systems", Balkan Journal of Electrical \& Computer Engineering, vol. 7, no. 3, pp. 269-275, July 2019.

[16] R. Çelikel, M. Yılmaz and A. Gündoğdu, "A voltage scanning-based MPPT method for PV power systems under complex partial shading conditions", Renewable Energy, vol. 184, pp. 361-373, 2022.

[17] R. Çelikel and A. Gündoğdu, "Comparison of PO and INC MPPT methods using FPGA In-The-Loop under different radiation conditons", Balkan Journal of Electrical and Computer Engineering, vol. 9, no. 2, pp. 114-122, 2021.

[18] Bosch Solar Services, http://bosch-solarenergy.de/en/customerservice/product/kundendienst-2.html (accessed: 25.03.2021)

\section{BIOGRAPHIES}

Mustafa Engin Başoğlu was born in 1988. He received the M.Sc. degree of Electrical Engineering at Kocaeli University, Turkey in 2013. He receives $\mathrm{Ph} . \mathrm{D}$. in 2017 with thesis "Development and implementation of a new maximum power point tracking method for photovoltaic systems". From 2012, he is research assistant in the department of Electrical Engineering in University Kocaeli. From 2020, he is associate professor in Electrical and Electronics Department of Gümüşhane University. His research interests include: photovoltaic systems, renewable energy, maximum power point tracking algorithms, power electronics, switch mode power supplies and control of electrical machines. 